\title{
Measuring the impact of the Affordable Care Act Medicaid expansion on access to primary care using an interrupted time series approach
}

\author{
Elizabeth A. Brown ${ }^{1 *} \mathbb{0}$, Brandi M. White ${ }^{2}$, Walter J. Jones ${ }^{3}$, Mulugeta Gebregziabher ${ }^{4}$ and Kit N. Simpson ${ }^{3}$
}

\begin{abstract}
Background: The Patient Protection and Affordable Care Act of 2010, commonly referred to as the Affordable Care Act (ACA), was created to increase access to primary care, improve quality of care, and decrease healthcare costs. A key provision in the law that mandated expansion of state Medicaid programme changed when states were given the option to voluntarily expand Medicaid. Our study sought to measure the impact of ACA Medicaid expansion on preventable hospitalization $(\mathrm{PH})$ rates, a measure of access to primary care.
\end{abstract}

Methods: We performed an interrupted time series analysis of quarterly hospitalization rates across eight states from 2012 to 2015. Segmented regression analysis was utilized to determine the impact of policy reform on PH rates.

Results: The Affordable Care Act's Medicaid expansion led to decreased rates of PH (improved access to care); however, the finding was not significant (coefficient estimate: $-0.0059, \mathrm{Cl}-0.0225,0.0107, p=0.4856$ ). Healthcare system characteristics, such as Medicaid spending per enrollee and Medicaid income eligibility, were associated with a significant decrease in rates of PH (improved access to care). However, the Medicaid-to-Medicare fee index (physician reimbursement) and states with a Democratic state legislature had a significant increase in rates of PH (poor access to care).

Conclusion: Health policy reform and healthcare delivery characteristics impact access to care. Researchers should continue evaluating such policy changes across more states over longer periods of time. Researchers should translate these findings into cost analysis for state policy-makers to make better-informed decisions for their constituents.

Contribution to knowledge: Ambulatory care-sensitive conditions are a feasible method for evaluating policy and measuring access to primary care. Policy alone cannot improve access to care. Other factors (trust, communication, policy-makers' motivations and objectives, etc.) must be addressed to improve access.

Keywords: Access, Primary care, Medicaid, Patient Protection and Affordable Care Act, Health policy, Interrupted time series analysis

*Correspondence: brownea@musc.edu

${ }^{1}$ Department of Clinical Sciences, College of Health Professions, Medical University of South Carolina, 151-B Rutledge Avenue, MSC 962, Charleston, SC 29425, USA

Full list of author information is available at the end of the article

\section{Background}

One of the most influential factors impacting access to primary care in the United States is the implementation of federal healthcare legislation, policies, and programmes. Although healthcare legislation aims to create equity in healthcare, many Americans still lack access to quality medical care for a host of reasons, including their race/ethnicity [1] or socioeconomic factors like income give appropriate credit to the original author(s) and the source, provide a link to the Creative Commons licence, and indicate if changes were made. The images or other third party material in this article are included in the article's Creative Commons licence, unless indicated otherwise in a credit line to the material. If material is not included in the article's Creative Commons licence and your intended use is not permitted by statutory regulation or exceeds the permitted use, you will need to obtain permission directly from the copyright holder. To view a copy of this licence, visit http://creativecommons.org/licenses/by/4.0/. The Creative Commons Public Domain Dedication waiver (http://creativecommons.org/publicdomain/zero/1.0/) applies to the data made available in this article, unless otherwise stated in a credit line to the data. 
[2] and employment [3]. In an effort to increase access to primary care, improve quality of care, and decrease unnecessary costs in healthcare, legislators created the Patient Protection and Affordable Care Act (PPACA) of 2010, commonly referred to as the Affordable Care Act (ACA) or "Obamacare". The ACA's fundamental provisions included mandates such as (a) expanding Medicaid eligibility to $138 \%$ of the federal poverty level (FPL) in all states, (b) modifying Medicaid eligibility, allowing individuals with low incomes and without dependents to be eligible for Medicaid, (c) requiring individuals to secure health insurance or face a tax penalty, and (d) allowing children to stay on their parents' health insurance until their 26th birthday [4].

\section{Conceptual framework}

Access to primary care is a versatile concept, incorporating an array of variables that influence the ability to receive and maintain care. According to the theoretical model-framework for the study of access-when examining access to care, the following personal and environmental factors can significantly influence access to care: health policy, delivery of care, individual characteristics, utilization of care, and patient satisfaction [5]. The framework identifies and discusses several variables that may either impede or promote access to care. The authors employ several constructs in Aday and Andersen's framework for the study of access, including healthcare policy, healthcare delivery, and sociodemographic characteristics, to guide the research study and select appropriate variables for analytic purposes (Fig. 1).

Regarding healthcare policy, former President Barack Obama and supporters aspired to increase access to primary care with the ACA, one of the most significant healthcare reforms in over 40 years. However, in June 2012, the Supreme Court "applied a theory of coercion" [6], in National Federation of Independent Business v. Sebelius, striking down the federal government's mandate for state Medicaid expansion without financial repercussions to states, thus giving states the option to voluntarily expand Medicaid or opt out of Medicaid expansion without any monetary penalties from the federal government [6]. The court's ruling modified the ACA and potentially had a detrimental impact on access to care, hospitals, and health outcomes for millions of Americans with low incomes, especially for people living in states that chose not to expand their Medicaid programme [7].

States with Republican governors were more likely to opt out of Medicaid expansion, while states with Democratic governors were more likely to choose to expand Medicaid [8]. Many governors in opt-out states cited constrained state budgets and uncertainty regarding the federal government's ongoing financial support towards Medicaid expansion; however, governors in states that expanded believed expansion would increase access by covering the uninsured population, improve health outcomes, and save tax dollars [8]. The Supreme Court ruling and policy-makers' attitudes towards the ACA

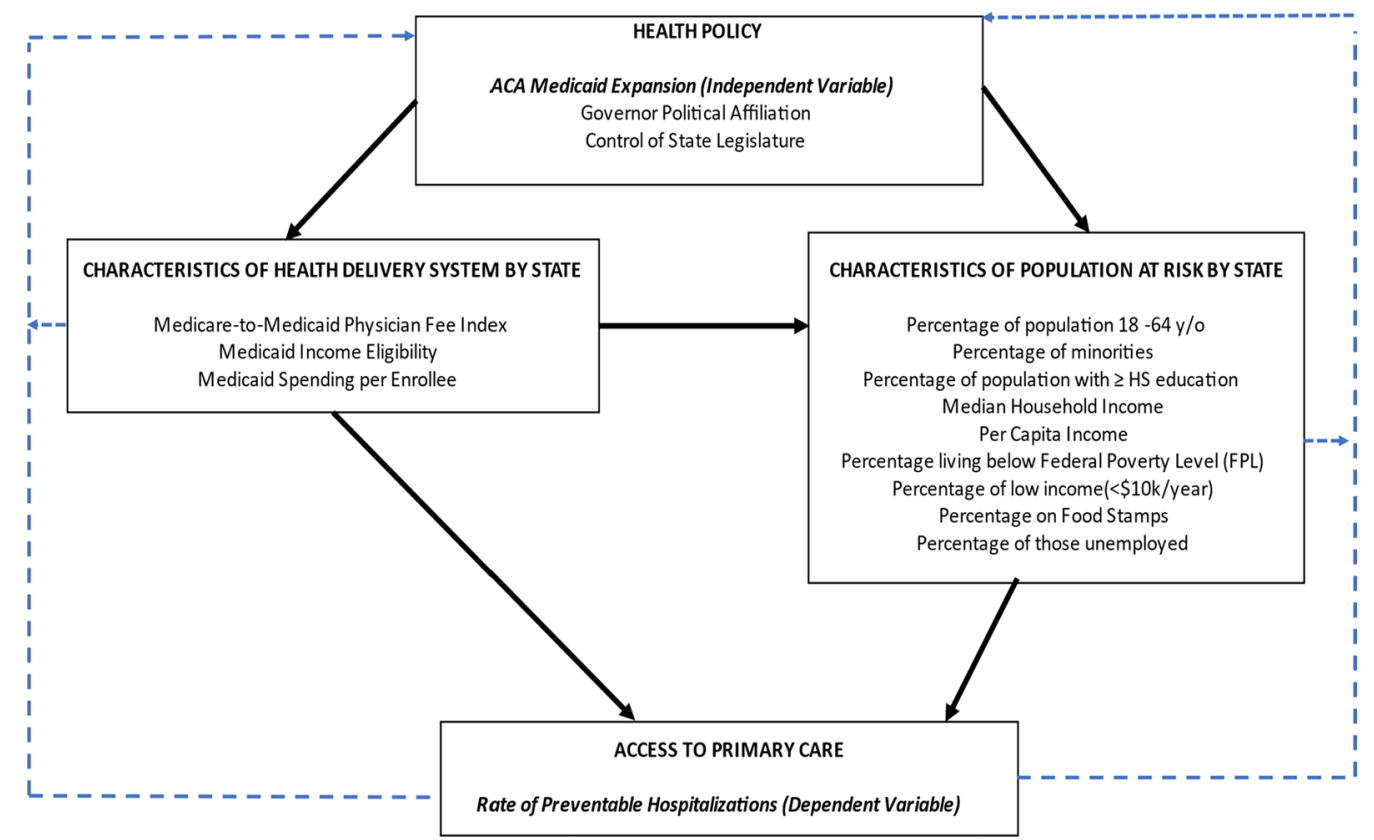

Fig. 1 Conceptual framework for access to primary care, Adapted from Aday and Andersen's framework for the study of access 
Medicaid expansion may have impacted primary care access.

\section{Purpose}

This study compared access to primary care-measured by the rate of preventable hospitalizations $(\mathrm{PH})$-in a cohort of four states that implemented the ACA Medicaid expansion on 1 January 2014 to a cohort of four states that did not expand their Medicaid programmes.

\section{Methods}

\section{Study design}

The ACA's Medicaid expansion allowed for a retrospective, quasi-experimental study using an interrupted time series (ITS) research design to evaluate the impact of the ACA Medicaid expansion on access to primary care. The ITS design allows for a change or intervention to separate time periods and compare the effect of the intervention; it is increasingly used in the evaluation of healthcare interventions such as healthcare policies and programmes [9]. ITS is a robust design for evaluating the effectiveness of a population-level intervention like Medicaid expansion that was implemented at a clearly defined point in time [10].

The intervention was the implementation of Medicaid expansion under the ACA effective 1 January 2014. We examined eight quarterly pre-intervention time points prior to implementation (1 January 2012-31 December 2013) and seven quarterly post-intervention time points after implementation (1 January 2014-30 September 2015). In 2015, fourth quarter hospital admissions (October through December) were not used due to the transition from International Classification of Diseases, Ninth Revision (ICD-9) codes to ICD-10 codes. Generally, it is suggested that researchers have 12 data points before and 12 data points after the intervention when using ITS [11]. However, researchers utilizing ITS methodology have used different number of data points before and after an intervention such as a policy change $[12,13]$.

\section{Study population}

Based on hospitalization data available at the time of this project, we selected four states that expanded Medicaid on 1 January 2014 (treatment group): Arizona (AZ), Kentucky (KY), New Jersey (NJ), and New York (NY). Then, we selected four states that chose not to expand Medicaid (control group): Florida (FL), Georgia (GA), South Carolina (SC), and Wisconsin (WI). Most of these states are more likely to be generalizable to the Southeast or Northeast United States.

Inclusion criteria include the following characteristics: (a) all payers (Medicaid, Medicare, private insurance, self-pay), (b) 18-64 years old, (c) all races, and (d) all hospitalizations with an ambulatory care-sensitive (ACS) condition as the primary discharge diagnosis. South Carolina hospitalization data included those aged 20-64 years due to administrative hospital data construction. We included all community hospitals that report patient discharge data to the Agency for Health Research and Quality's (AHRQ) Healthcare Cost and Utilization Project (HCUP) State Inpatient Databases (SID). Federal or veteran hospitals were not included in the study sample.

\section{Data sources}

The AHRQ HCUP SID provided administrative hospital data, patient demographics, ICD-9 diagnosis codes, total charges, length of stay, and expected payment source for all hospital inpatient stays in community hospitals in each state [14].

Data from the 2010 Census and 2015 population estimates were used to compute annual population estimates (18-64 years old) from 2012 to 2015 [16]. Aggregated Census data (2011-2015) were used to report education and median household income (MHI). The 2015 American Community Survey provided the percentage of unemployed persons [17].

The National Conference of State Legislatures (NCSL) provided data on state legislature control [18]. The Henry J. Kaiser Family Foundation (KFF) provided information about the Medicaid-to-Medicare fee index and Medicaid spending per enrollee $[19,20]$. KFF also reports state Medicaid income eligibility limits [21].

\section{Independent variables}

The main independent variables were state Medicaid expansion status, post-Medicaid expansion (time), and an interaction term (state Medicaid expansion status" postMedicaid expansion). State Medicaid expansion status was a dichotomous variable and indicated whether a state expanded its Medicaid programme as of 1 January $2014(0=$ No vs $1=$ Yes). Post-Medicaid expansion (time variable) was dichotomous $(0=$ before 1 January 2014 vs $1=$ after 1 January 2014 . The interaction term was a binary variable indicating time before and after expansion, interacted with the time variable to assess change in the rate of $\mathrm{PH}$ after Medicaid expansion.

\section{Sociodemographic model}

The following state characteristics were considered independent variables in the sociodemographic model: (a) percentage of population 18-64 years old, (b) percentage of minorities, (c) percentage of people 25 years and older who had a bachelor's degree from 2011 to 2015, (d) percentage of people unemployed, and (e) MHI from 2011 to 2015 (reported in 2015 dollars). 


\section{Health delivery system model}

The 2014 Medicaid-to-Medicare fee index was a numeric value indicating the amount state Medicaid programmes reimbursed physicians for primary care services compared to Medicare primary care services. Medicaid income eligibility was a numeric value representing the FPL for Medicaid eligibility prior to and after 1 January 2014. Medicaid spending per adult enrollee was the dollar amount each state spent on its adult Medicaid enrollees in fiscal year 2011.

\section{Health policy model}

Republican state governor was a dichotomous variable $(0=$ Democratic vs $1=$ Republican $)$ and measured the period when the state had a Republican governor. The Republican state legislature was a dichotomous variable ( $0=$ Democratic vs $1=$ Republican) and measured the period when the Republican party had control of the state legislature.

\section{Dependent variable}

The dependent variable was the change in the rate of $\mathrm{PH}$ per 10,000 persons due to ACS conditions in adults aged 18-64 years from January 2012 to September 2015 for selected states.

\section{$\mathrm{PH}$}

$\mathrm{PH}$ were defined as a hospitalization with an ACS condition as the principal discharge diagnosis and were used to measure access to primary care. The use of ACS conditions is a validated method to measure access to primary care [22]. Theoretically, ACS conditions are illnesses or diagnoses for which, with proper primary care, hospitalizations can be avoided if the disease is appropriately managed in the community setting [2]. Examples of some ACS conditions included in our study were asthma, bacterial pneumonia, dehydration, hypertension, and diabetes (Additional file 1).

\section{Statistical analysis}

We performed bivariate analysis to identify significant differences in data between the two cohorts: Medicaid expansion states $(n=4)$ and non-Medicaid expansion states $(n=4)$. Correlation between variables was examined, and moderately to highly correlated variables $(r>0.65)$ were excluded from the final analysis [23]. We performed $t$-tests for continuous data and chi-square tests for categorical data.

We used segmented regression for ITS (SR-ITS) described by Wagner and colleagues as the primary analysis approach [11]. The regression for each segment was based on a general linear model (GLM), which allowed us to estimate the level and trend changes associated with the intervention, and it also allowed us to control for baseline level and trend. We used the time series for each outcome to establish an underlying trend, which is "interrupted" by an intervention at a known point in time-1 January 2014. We assessed the effect of the intervention against the counterfactual (hypothetical scenario under which the intervention did not take place, and the trend continues unchanged given the pre-intervention period). We differentiated the pre-intervention period and the post-intervention period and the implementation period so that it could be considered separately when assessing the effect of the intervention.

A GLM was used to analyse unadjusted and adjusted models. Since we used only eight states for the analysis, we analysed separate regression models based on factors in the Aday and Andersen framework for the study of access to care [5]. The explanatory model consisted of one independent variable, Medicaid expansion status (0 vs 1), where 0 was "No" and 1 was "Yes". Next, the base model included an interaction term (Medicaid expansion status*time), which accounted for the trend over time by quarters. The subsequent three models accounted for various characteristics, including sociodemographic factors, health delivery system factors, and health policy factors.

Main effects were considered significant at alpha $<0.05$. The interaction term was considered significant at alpha $<0.15$, indicating a significant change in the rate of $\mathrm{PH}$ due to ACS conditions after the implementation of Medicaid expansion. [24] We used SAS 9.4 software to complete all data analysis (SAS Institute Inc., Cary, NC).

An institutional review board deemed this research not to be human subject research since data used de-identified public-use data. The appropriate persons completed the HCUP Data Use Agreement (DUA) online training.

\section{Results}

There were 2,103,114 PHs in eight states from January 2012 to September 2015. Approximately $52.1 \%$ of these PHs occurred in the cohort of states that did not expand Medicaid (Table 1). States that expanded Medicaid had a higher proportion of individuals with a bachelor's degree (30.2\% vs $27.4 \%, p=0.0194)$ and reported a higher $\mathrm{MHI}$ $(\$ 56,240$ vs $\$ 49,006, p=0.0005)$.

On average, states that expanded Medicaid had a higher mean rate of $\mathrm{PH}$ per 10,000 persons than states that did not expand Medicaid (28.93/10,000 vs 26.94/10,000) (Fig. 2).

In 2014, states that expanded Medicaid eligibility limits had a mean $138 \%$ of the FPL compared to $60.2 \%$ of the FPL for states that did not expand (Table 2). Medicaid 
Table 1 Demographic variables and primary care access by Affordable Care Act Medicaid expansion status, 2012-2015

\begin{tabular}{|c|c|c|c|}
\hline Demographic variables $^{a}$ & NME $^{\text {b }}$ states & $\mathrm{ME}^{\mathrm{C}}$ states & $p$-value \\
\hline \multicolumn{4}{|l|}{ Access to care $(n, \%)$} \\
\hline $\begin{array}{l}\text { Preventable hospitaliza- } \\
\text { tions }\end{array}$ & $1,096,631(52.1)$ & $1,006,483(47.9)$ & 0.2670 \\
\hline \multicolumn{4}{|l|}{ State population } \\
\hline 18-64 years old & $6,127,025$ & $6,191,002$ & 0.8776 \\
\hline \multicolumn{4}{|l|}{ Race (\%) } \\
\hline Minorities & 41.7 & 38.9 & 0.9457 \\
\hline \multicolumn{4}{|l|}{ Education (\%) } \\
\hline High school graduate & 87.3 & 86.1 & 0.0676 \\
\hline Bachelor's degree & 27.4 & 30.2 & 0.0194 \\
\hline \multicolumn{4}{|l|}{ Income (\$) } \\
\hline $\mathrm{MHI}$ & 49,006 & 56,240 & 0.0005 \\
\hline Per capita income & 26,381 & 29,865 & 0.0194 \\
\hline \multicolumn{4}{|l|}{ Poverty (\%) } \\
\hline Below FPL & 15.3 & 15.6 & 0.1704 \\
\hline Income $<10 \mathrm{k}$ & 7.2 & 7.6 & 0.2244 \\
\hline Food stamps & 14.0 & 13.5 & 0.2546 \\
\hline Unemployment & 7.0 & 7.2 & 0.2595 \\
\hline \multicolumn{4}{|c|}{ Healthcare delivery characteristics } \\
\hline Physician fee index $(\$)^{d}$ & 0.60 & 0.58 & 0.8029 \\
\hline $\begin{array}{l}\text { Medicaid \$ per enrollee } \\
(\$)^{e}\end{array}$ & 3,336 & 5,120 & $<0.0001$ \\
\hline $\begin{array}{l}\text { Income eligibility, FPL } \\
(\%)^{f}\end{array}$ & 80.6 & 124.1 & $<0.0001$ \\
\hline \multicolumn{4}{|l|}{ Governor political affiliation } \\
\hline Democratic & $0(0.0)$ & $27(100.0)$ & $<0.0001$ \\
\hline Republican & $62(64.6)$ & $34(35.4)$ & \\
\hline \multicolumn{4}{|l|}{ Control of state legislature } \\
\hline Democratic & $0(0.0)$ & $45(100.0)$ & $<0.0001$ \\
\hline Republican & $62(79.5)$ & $16(20.5)$ & \\
\hline
\end{tabular}

Italic values are significant values

${ }^{a} t$-test for continuous variables and chi-square test for categorical variables

${ }^{b}$ NME: Non-Medicaid expansion states include South Carolina, Wisconsin, Georgia, and Florida

'ME: Medicaid expansion states include Arizona, Kentucky, New Jersey, and New York

${ }^{\mathrm{d}}$ Medicaid-to-Medicare fee index

e Medicaid spending per enrollee

${ }^{f}$ Average of pre- and post-ACA FPL Medicaid income eligibility limits for parents of dependent children (in a family of three)

spending per enrollee was higher in Medicaid expansion states than in states that did not expand their Medicaid programme (\$5103 vs \$3342) in fiscal year 2011.

In the unadjusted model, Medicaid expansion was associated with a slight but nonsignificant increase in $\mathrm{PH}$ rates (coefficient estimate 0.0713, CI $-0.0076,0.1503$, $p=0.0764$ ) (Table 3). After accounting for trend over time, the change in $\mathrm{PH}$ rates in Medicaid expansion states declined; however, this finding was not significant (coefficient estimate -0.0059, CI $-0.0225,0.0107$, $p=0.4856$ ).

When we controlled for healthcare delivery characteristics, states that expanded their Medicaid programme saw a significant increase in the change in $\mathrm{PH}$ rates (coefficient estimate 0.0237, CI 0.0067, 0.0406, $p=0.0061$ ). Medicaid spending per enrollee and Medicaid income eligibility were associated with significant decreases in rates of PH (improved access to care) (Table 3).

States that expanded Medicaid had lower rates of $\mathrm{PH}$ when controlling for state policy factors, but this difference was not significant. States where Democrats had control of the state legislature saw a significant increase in rates of $\mathrm{PH}$ (coefficient estimate 0.1711, CI 0.0273, $0.3150, p=0.0197)$ (Table 3).

\section{Discussion}

Our findings illustrate a slight decrease in the rate of $\mathrm{PH}$ over time for states that expanded Medicaid. Although not significant, our study shows that Medicaid expansion may have had a positive impact on primary care access. The most important aspect of this study was the health delivery system characteristics and their impact on $\mathrm{PH}$ rates across the states.

Our findings are similar to previous studies evaluating Medicaid expansion and its impact on access to primary care. In Oregon, after Medicaid expansion in 1994, researchers reported that annual $\mathrm{PH}$ rates increased from 46.1 to 54.9 per 10,000 persons [25]. In adjusted analysis, they reported that individuals had a higher likelihood of experiencing a PH $(\mathrm{OR}=1.18, p<0.001)$ [25]. An increase in $\mathrm{PH}$ rates should not signal policy failure but may hint at the need for more or better primary care services [25]. In another study in Massachusetts, researchers found that emergency department (ED) utilization for ACS conditions increased by 6.7 percentage points after healthcare reform $(21.1 \%$ to $27.8 \%, p<0.05)$ [26]. The authors note that access to primary care depends on primary care physician availability and convenience of emergency rooms; further, it may take time to see patients change care-seeking behaviours, which could also impact rates of $\mathrm{PH}$ [26]. Although Medicaid expansion may decrease the number of uninsured, it appears that after policy reform, poor access to care is still an issue, which may be for various reasons, including low Medicaid reimbursement, pent-up healthcare demand, ED convenience and hours, and illness severity.

\section{State health delivery system characteristics}

Several state-level health delivery system characteristics (e.g., Medicaid income eligibility and Medicaid dollars spent per enrollee), which are derivative of 


\section{Mean Rate of Preventable Hospitalizations by Medicaid Expansion Status,}

18-64 years old, 2012-2015

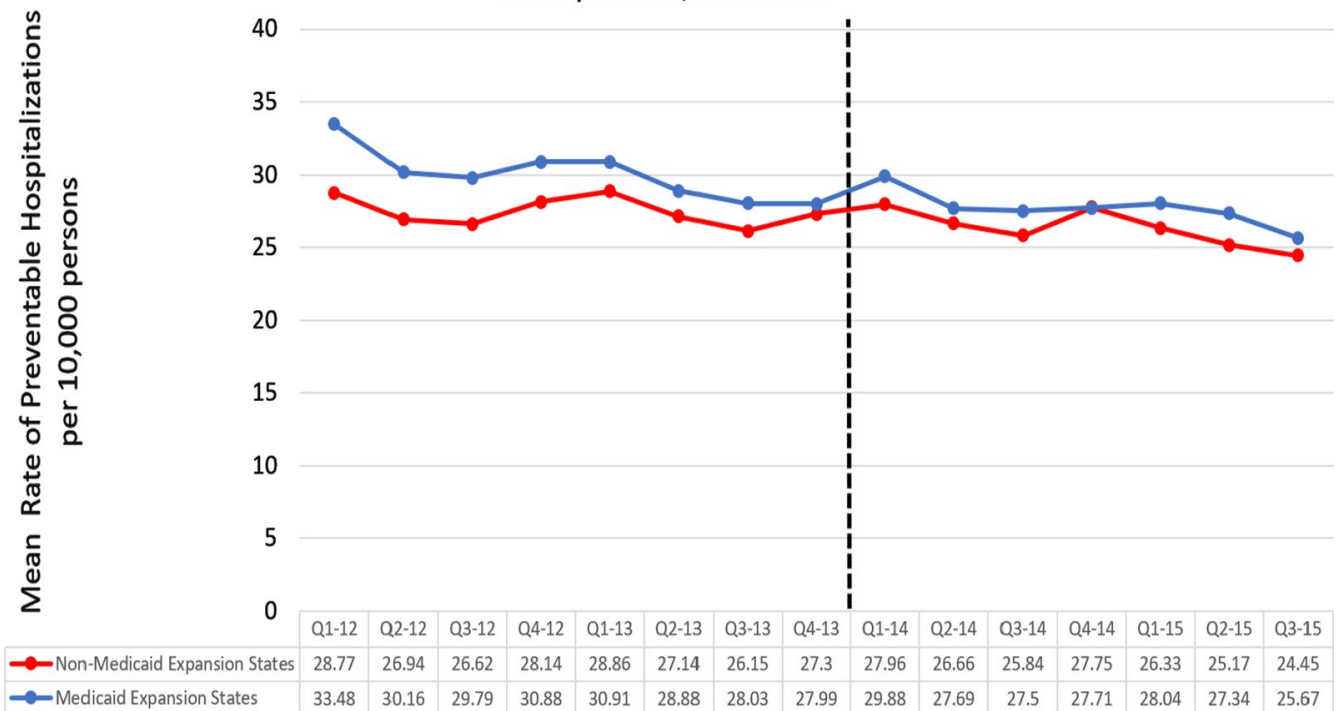

Fig. 2 Mean rate of preventable hospitalizations per 10,000 persons by Medicaid expansion status, 2012-2015

Table 2 Snapshot of health delivery system characteristics for selected states

\begin{tabular}{|c|c|c|c|}
\hline States & $\begin{array}{l}2014 \text { Medicaid income eligibility, } \\
\%^{\mathrm{a}}\end{array}$ & $\begin{array}{l}\text { Medicaid spending per enrollee, } \\
\$^{\mathrm{b}}\end{array}$ & $\begin{array}{l}\text { Medicaid-to- } \\
\text { Medicare fee } \\
\text { index, } \$^{c}\end{array}$ \\
\hline \multicolumn{4}{|l|}{ Medicaid expansion } \\
\hline Arizona & 138 & 6,131 & 0.73 \\
\hline Kentucky & 138 & 5,000 & 0.67 \\
\hline New Jersey & 138 & 4,687 & 0.42 \\
\hline New York & 138 & 4,596 & 0.44 \\
\hline Mean for Medicaid expansion states & 138 & 5,103 & 0.57 \\
\hline \multicolumn{4}{|l|}{ Non-Medicaid expansion states } \\
\hline Florida & 35 & 2,880 & 0.48 \\
\hline Georgia & 39 & 4,174 & 0.65 \\
\hline South Carolina & 67 & 3,583 & 0.70 \\
\hline Wisconsin & 100 & 2,731 & 0.48 \\
\hline Mean for non-Medicaid expansion states & 60.2 & 3,342 & 0.58 \\
\hline
\end{tabular}

${ }^{a}$ Medicaid income eligibility -2014 data, ACA FPL income eligibility limits for parents of dependent children (in a family of three)

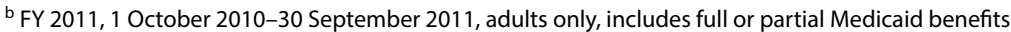

c Medicaid-to-Medicare fee index-2014 data

healthcare policy, appear to be significantly associated with decreases in the rate of $\mathrm{PH}$ (improved access to care). The increase in Medicaid income eligibility and what states paid per Medicaid enrollee may have allowed more people to gain health insurance coverage, which may have increased access to care and led to a significant decrease in rates of $\mathrm{PH}$.
In our study, the Medicaid-to-Medicare fee index appeared to be associated with higher rates of $\mathrm{PH}$ or worse access to primary care. This may be due to other factors that were not measured in the study. For example, if physicians are reimbursed at a higher rate for primary care services under Medicaid, ideally, we assume that more physicians would accept and treat more patients with Medicaid insurance, which could improve 
Table 3 Regression models for rates of preventable hospitalizations

\begin{tabular}{|c|c|c|}
\hline \multicolumn{3}{|c|}{ Coefficient estimates ( $95 \%$ confidence intervals) } \\
\hline Variables & Coefficient estimate & $p$-value \\
\hline \multicolumn{3}{|l|}{ Medicaid expansion (explanatory model) } \\
\hline Non-Medicaid expansion states & ref & \\
\hline Medicaid expansion states & $0.0713(-0.0076,0.1503)$ & 0.0764 \\
\hline \multicolumn{3}{|l|}{ Medicaid expansion*time (base model) } \\
\hline Non-Medicaid expansion states*time & ref & \\
\hline Medicaid expansion states*time & $-0.0059(-0.0225,0.0107)$ & 0.4856 \\
\hline \multicolumn{3}{|l|}{ Sociodemographic characteristics } \\
\hline Non-Medicaid expansion states*time & ref & \\
\hline Medicaid expansion states*time & $-0.0063(-0.0221,0.0094)$ & 0.4293 \\
\hline Minorities & $-0.0042(-0.0160,0.0077)$ & 0.4887 \\
\hline Bachelor's degree & $0.0067(-0.0796,0.0930)$ & 0.8782 \\
\hline Unemployment & $0.1068(0.0313,0.1824)$ & 0.0056 \\
\hline Median household income & $-0.0000(-0.0000,0.0000)$ & 0.3813 \\
\hline \multicolumn{3}{|l|}{ Health delivery system characteristics } \\
\hline Non-Medicaid expansion states*time & ref & \\
\hline Medicaid expansion states*time & $0.0237(0.0067,0.0406)$ & 0.0061 \\
\hline Medicaid-to-Medicare fee index & $0.9501(0.4733,1.4269)$ & $<0.0001$ \\
\hline Medicaid spending per enrollee & $-0.0003(-0.0004,-0.0002)$ & $<0.0001$ \\
\hline Medicaid income eligibility & $-0.0046(-0.0055,-0.0036)$ & $<0.0001$ \\
\hline \multicolumn{3}{|l|}{ Health policy characteristics } \\
\hline Non-Medicaid expansion states*time & ref & \\
\hline Medicaid expansion states*time & $-0.0042(-0.0211,0.0127)$ & 0.6273 \\
\hline Republican state legislature & ref & \\
\hline Democratic state legislature & $0.1711(0.0273,0.3150)$ & 0.0197 \\
\hline Republican state governor & ref & \\
\hline Democratic state governor & $0.1013(-0.0179,0.2205)$ & 0.0957 \\
\hline
\end{tabular}

Italic values are significant values

access to care and decrease rates of $\mathrm{PH}$. However, this may not be the case at all. Researchers cite other factors like an increase in healthcare demand coupled with a declining number of providers who accept Medicaid that could impact access to care [27]. If there is a decrease in the number of providers who accept Medicaid, it could be due to a state's low reimbursement rates for Medicaid primary care services. For example, for every $\$ 1.00$ that Medicare pays for primary care services, Medicaid pays $\$ 0.48$ for primary care services in New York (Medicaid expansion state) compared to $\$ 0.59$ in the United States or \$0.48 in Florida (nonMedicaid expansion state) [19].

Another factor that may contribute to our findings is the number of primary care physicians or medically underserved areas in states we examined. The availability of physicians could impact access to care. In one study, researchers found that as the number of family practitioners (FP) and general practitioners (GP) increased, the rate of avoidable hospitalizations decreased [28].
Researchers reported that for every increase in either a FP or GP, there was a 2.75 reduction in $\mathrm{PH}$ per 10,000 people [28]. Thus, it is plausible that the number of physicians (or lack thereof) could contribute to more $\mathrm{PH}$, which is an indicator of poor primary care access.

\section{State sociodemographic characteristics}

Our study shows that as the percentage of unemployment increases, so does the rate of $\mathrm{PH}$. This may be due to other socioeconomic factors, including education, income, and even stress, which could impact health status. Individuals who are unemployed, lack monetary resources, are stressed about finances, and do not have health insurance may delay care and be hospitalized for preventable conditions. Several studies in the accessto-care literature have reported on delaying care due to costs [27, 29-31]. 


\section{State health policy characteristics}

State legislatures controlled by Democrats saw a significant increase in rates of $\mathrm{PH}$ over time compared to Republican-controlled state legislatures. This could be due to the nature of Republican lawmakers, who promote more fiscally conservative policies that could impact health delivery system characteristics, leading to lower Medicaid income eligibility limits and the amount of money spent per Medicaid enrollee.

\section{Individual-level characteristics}

A health insurance card does not lead to immediate access to healthcare [32]. An insurance card does not create convenient office hours or guarantee transportation to a medical provider, and does not address the unique needs of each patient [32]. In the Framework for the Study of Access [5], lack of transportation and special needs of the individual would be categorized as "characteristics of population at risk", and convenient office house would fall under "consumer satisfaction". In this same framework, all variables under "consumer satisfaction", such as convenience, costs, quality, and courtesy, were not measured in this study and can certainly impact an individual's access to primary care.

Another factor at the individual level may be that, although individuals gained a health insurance card, they do not necessarily know how to access primary care or have a trusting relationship with a provider they feel comfortable confiding in with their personal health information. According to the Agency for Healthcare Research and Quality [33], communication and trust are essential components in promoting access to healthcare. The time needed to (a) have individuals familiarize themselves with primary care practices and (b) develop a trusting relationship with a primary care provider is quite an important factor, and this aspect in healthcare practice takes time, especially for those who may have never had health insurance or a primary care provider. As more people gain insurance under the ACA and find a usual source of care or primary care doctor, they may be less likely to have a $\mathrm{PH}$. We may need more time to see individuals find and develop a relationship with a trustworthy primary care provider before seeing a significant decrease in the rates of $\mathrm{PH}$.

\section{State Medicaid characteristics}

A separate factor at the state level was the approach to how Medicaid expansion states marketed Medicaid insurance to eligible populations, which was an unobserved factor in our research study. Medicaid expansion states may have varied by leadership, collaboration efforts, and other factors [34]. Medicaid expansion states may have had different strategies to target underserved groups or provide enrollment assistance like bilingual staff and interpretation services [34]. It is plausible that these unobserved characteristics in Medicaid expansion states could impact the rates of $\mathrm{PH}$. If Medicaid expansion states were slow to market Medicaid or did not target traditionally underserved populations (e.g., minorities, uninsured, low-income groups), individuals may have missed the opportunity to get health insurance and endured poor access to primary care, which could lead to an increase in rates of $\mathrm{PH}$ in Medicaid expansion states.

\section{Limitations}

Our study had several limitations, including possible administrative errors with ICD-9 codes. There was also an inability to measure unobserved differences in populations across the different states, including the differences in Medicaid enrolment and marketing strategies and patient care-seeking behaviours. Further, the analytical approach used may not capture nonlinear relationships between variables. Selection bias may be an issue, as authors utilized hospitalization data available at the time of the study. There are various methods to measure access to care, including using self-report or survey data and data from medically underserved areas. Lastly, findings are limited to the population studied.

\section{Conclusion}

It is important to continue examining the impact of Medicaid expansion on access to primary care based on our findings regarding the health delivery system characteristics, a product of health policy reform. While the ACA Medicaid expansion happened approximately 10 years ago, the hospital administrative data to measure access to primary care after Medicaid expansion are still relatively new, including the transition from ICD-9 codes to ICD-10 codes. Research examining the effects of ACA Medicaid expansion is still in its early stages. As more administrative data become available, researchers should continue analysing more state hospital data over longer periods of time to see whether there is a significant effect on primary care access. Lastly, researchers should translate these findings into cost analysis for state policy-makers to make better-informed decisions for their constituents.

\section{Supplementary Information}

The online version contains supplementary material available at https://doi. org/10.1186/s12961-021-00730-0.

Additional file 1: List of Ambulatory Care Sensitive (ACS) conditions and ICD-9 codes used to define preventable hospitalizations. 


\section{Acknowledgements}

Data and analytic support were provided through the Comparative Effectiveness and Data Analytics Research Resource Core (CEDAR), funded by the Medical University of South Carolina Office of the Provost, and by the South Carolina Clinical and Translational Research (SCTR) Institute, with an academic home at the Medical University of South Carolina, through NIH grant numbers UL1 RR029882 and UL1 TR001450.

\section{Authors' contributions}

The research idea was conceived by KS, EB, BW, and WJ. The analysis was done by EB. The first draft of the manuscript was prepared by EB. MG reviewed the paper and provided substantial edits. All co-authors participated substantially in the writing and critical review of the manuscript. All authors read and approved the final manuscript.

\section{Funding}

Not applicable.

\section{Availability of data and materials}

The data that support the findings of this study are available from the Agency for Healthcare Research and Quality, but restrictions apply to the availability of these data, which were used under license for the current study, and so are not publicly available.

\section{Declarations}

\section{Ethics approval and consent to participate}

The Medical University of South Carolina Institutional Review Board (IRB) deemed this research to not be human subject research since the data used de-identified public-use data. The appropriate persons completed the HCUP Data Use Agreement (DUA) online training.

\section{Consent for publication}

Not applicable.

\section{Competing interests}

The authors declare that they have no competing interests.

\section{Author details}

${ }^{1}$ Department of Clinical Sciences, College of Health Professions, Medical University of South Carolina, 151-B Rutledge Avenue, MSC 962, Charleston, SC 29425, USA. ${ }^{2}$ Division of Health Sciences, Education, and Research, College of Health Sciences, University of Kentucky, Room 209C Wethington Building, 900 South Limestone Street, Lexington, KY 40536-0200, USA. ${ }^{3}$ Department of Healthcare Leadership and Management, College of Health Professions, Medical University of South Carolina, 151-B Rutledge Ave, MSC 962, Charleston, SC 29425, USA. ${ }^{4}$ Department of Public Health Sciences, College of Medicine, Medical University of South Carolina, 135 Cannon Street, Charleston, SC 29425, USA.

Received: 16 December 2020 Accepted: 20 April 2021 Published online: 06 May 2021

\section{References}

1. Gaskin DJ, Hoffman C. Racial and ethnic differences in preventable hospitalizations across 10 states. Med Care Res Rev. 2000;57(Suppl 1):85-107.

2. Billings J, Zeitel L, Lukomnik J, et al. Impact of socioeconomic status on hospital use in New York City. Health Aff (Millwood). 1993;12:162-73.

3. Ricketts TC, Randolph R, Howard HA, et al. Hospitalization rates as indicators of access to primary care. Health Place. 2001;7:27-38.

4. Kaiser Family Foundation. Summary of the Affordable Care Act. https:// www.kff.org/health-reform/fact-sheet/summary-of-the-affordable-careact/. Published 2013. Accessed April 2, 2021.

5. Aday LA, Andersen R. A framework for the study of access to medical care. Health Serv Res. 1974;9:208-20.

6. Musumeci M. A guide to the Supreme Court's Affordable Care Act decision. https://www.kff.org/health-reform/issue-brief/a-guide-to-the-supre me-courts-affordable/. Published 2012. Accessed 1 July 2019.
7. Graves JA. Medicaid expansion opt-outs and uncompensated care. N Engl J Med. 2012;367(25):2365-7.

8. Sommers BD, Epstein AMUS. governors and the Medicaid expansion-no quick resolution in sight. N Engl J Med. 2013;368:496-9.

9. Zhang F, Wagner AK, Soumerai SB, et al. Methods for estimating confidence intervals in interrupted time series analyses of health interventions. J Clin Epidemiol. 2009;62:143-8.

10. Bonell CP, Hargreaves J, Cousens S, et al. Alternatives to randomisation in the evaluation of public health interventions: design challenges and solutions. J Epidemiol Community Health. 2011;65(7):582-7.

11. Wagner AK, Soumerai SB, Zhang F, et al. Segmented regression analysis of interrupted time series studies in medication use research. J Clin Pharm Ther. 2002;27:299-309.

12. Chen C, Scheffler G, Chandra A. Massachusetts' health care reform and emergency department utilization. N Engl J Med. 2011;365(12):e25.

13. Stryjewski TP, Zhang F, Eliott D, Wharam JF. Effect of Massachusetts health reform on chronic disease outcomes. Health Serv Res. 2014;49(Suppl 2):2086-103.

14. Agency for Healthcare Research and Quality. Overview of the State Inpatient Databases (SID). https://www.hcup-us.ahrq.gov/sidoverview. jsp. Published 2019. Accessed 2 Feb 2020.

15. United States Census Bureau-a. Annual estimates of the resident population for the United States, Regions, States, and Puerto Rico: April 1, 2010 to July 1, 2016. https://www.census.gov/data/tables/2016/demo/ popest/nation-total.html. Published 2017. Accessed 25 July 2019.

16. United States Census Bureau-b. QuickFacts. https://www.census.gov/ quickfacts/table/PST045216/00. Published n.d. Accessed 25 July 2019.

17. United States Census Bureau American Community Survey. 2011-2015 ACS 5-year data profiles. https://www.census.gov/programs-surveys/ acs/ Published n.d. Accessed 5 June 2019.

18. National Conference of State Legislatures. State partisan composition. http://www.ncsl.org/research/about-state-legislatures/partisan-compo sition.aspx. Published 2019. Accessed 5 June 2019.

19. The Henry J. Kaiser Family Foundation-a. Medicaid-to-Medicare fee index. http://kff.org/medicaid/state-indicator/medicaid-to-medic are-fee-index/?currentTimeframe $=0 \&$ sortModel=\%7B $\% 22$ colld $\% 22: \%$ 22Location\%22,\%22sort\%22:\%22asc\%22\%7D. Published n.d. Accessed 25 July 2019

20. The Henry J. Kaiser Family Foundation-b. Medicaid spending per enrollee (full or partial benefit). https://www.kff.org/medicaid/stateindicator/medicaid-spending-per-enrollee/?currentTimeframe $=0 \&$ sortModel=\%7B\%22colld\%22:\%22Location\%22,\%22sort\%22:\%22asc\% 22\%7D. Published n.d. Accessed 5 June 2019.

21. The Henry J. Kaiser Family Foundation-c. Trends in Medicaid income eligibility limits. https://www.kff.org/data-collection/trends-in-medic aid-income-eligibility-limits/ Published n.d. Accessed 25 July 2019.

22. Agency for Healthcare Research Quality. AHRQ quality indicatorsguide to prevention quality indicators: hospital admission for ambulatory care sensitive conditions. Rockville: Report agency for Healthcare Research Quality; 2001. p. 2001.

23. Portney LG, Watkins MP. Foundations of clinical research: Applications to practice, 3rd ed. Upper Saddle River, NJ: Pearson/Prentice Hall, 2009, p. 525.

24. Brown EA, Gebregziabher M, Kamen DL, White BM, Williams EM. Examining racial differences in access to primary care for people living with lupus: use of ambulatory care sensitive conditions to measure access. Ethn Dis. 2020;30(4):611-20. https://doi.org/10.18865/ed.18830.18864. 18611.

25. Saha S, Solotaroff R, Oster A, Bindman AB. Are preventable hospitalizations sensitive to changes in access to primary care? The case of the Oregon Health Plan. Med Care. 2007;45(8):712-9.

26. Smulowitz PB, Lipton R, Wharam JF, et al. Emergency department utilization after the implementation of Massachusetts health reform. Ann Emerg Med. 2011;58(3):225-234 e221.

27. Long SK, Stockley K. The impacts of state health reform initiatives on adults in New York and Massachusetts. Health Serv Res. 2011;46:365-87.

28. Parchman ML, Culler S. Primary care physicians and avoidable hospitalizations. J Fam Pract. 1994;39(2):123-8. 
29. Sommers BD, Blendon RJ, Orav EJ, et al. Changes in utilization and health among low-income adults after Medicaid expansion or expanded private insurance. JAMA Intern Med. 2016;176:1501-9.

30. Sommers BD, Blendon RJ, Orav EJ. Both the "Private Option" and traditional Medicaid expansions improved access to care for low-income adults. Health Aff (Millwood). 2016;35:96-105.

31. Golberstein E, Gonzales G, Sommers BD. California's early ACA expansion increased coverage and reduced out-of-pocket spending for the state's low-income population. Health Aff (Millwood). 2015:34:1688-94.

32. Billings J, Teicholz N. Uninsured patients in District of Columbia hospitals. Health Aff (Millwood). 1990;9:158-65.

33. Agency for Healthcare Research Quality. National healthcare quality and disparities reports. Report, Agency for Healthcare Research Quality, Rockville, MD, 2014.
34. Artiga S, Rudowitz R, Tolbert J. Outreach and enrollment strategies for reaching the Medicaid eligible but uninsured population. https://www. kff.org/medicaid/issue-brief/outreach-and-enrollment-strategies-forreaching-the-medicaid-eligible-but-uninsured-population/ Published 2016. Accessed 1 July 2019.

\section{Publisher's Note}

Springer Nature remains neutral with regard to jurisdictional claims in published maps and institutional affiliations.
Ready to submit your research? Choose BMC and benefit from:

- fast, convenient online submission

- thorough peer review by experienced researchers in your field

- rapid publication on acceptance

- support for research data, including large and complex data types

- gold Open Access which fosters wider collaboration and increased citations

- maximum visibility for your research: over $100 \mathrm{M}$ website views per year

At BMC, research is always in progress.

Learn more biomedcentral.com/submissions 